\title{
Fetus papyraceous in a twın pregnancy: a case report without any maternal and fetal complications
}

\author{
Murat Bozkurt, ${ }^{1}$ Duygu Kara ${ }^{2}$
}

Keywords: fetus papyraceous, twin pregnancy, fetal death, pregnancy outcome, fetal resorption

\begin{abstract}
Fetus papyraceous is defined as a compressed fetus, the mummified, parchment-like remains of a dead twin that is retained in-utero after intrauterine death in the second trimester. We report a case of fetus papyraceous (FP) in a diamniotic and dichorionic pregnancy with no maternal and fetal complications during pregnancy or the post-partum period.
\end{abstract}

${ }^{1}$ Department of Obstetrics and Gynecology, Universal Hospitals Group, Malatya, Turkey

${ }^{2}$ Department of Radiology, Mus State Hospital, Mus, Turkey

\section{INTRODUCTION}

Fetus papyraceous is defined as a compressed fetus, the mummified, parchment-like remains of a dead twin that is retained in-utero after intrauterine death in the second trimester. The incidence of fetus papyraceous has been reported to be 1 in 17,000 to 20,000 pregnancies. ${ }^{1}$ It occurs in the setting of multiple gestation in the early second trimester, and the other fetus(es) continue to grow. When the fetus dies in early pregnancy, the amniotic fluid and placental tissue are absorbed and the fetus is compressed between the membranes with the coliving twin.

\section{CASE REPORT}

A 25 year-old 3rd gravida woman was admitted to the Taksim Education and Research Hospital at 39 gestational weeks with active travail. The patient had two normal previous obstetrical deliveries. For the current pregnancy, the patient had no antenatal care; therefore, sonographic evaluation was not available. Obstetric sonography was performed immediately prior to delivery and demonstrated a single intrauterine pregnancy with the following measurements: biparietal diameters, 96 $\mathrm{mm}$ (37 weeks, 4 days); femur length, $71 \mathrm{~mm}$ (37 weeks, 1 day); abdominal circumferences, $340 \mathrm{~mm}$ (37 weeks, 3

Please cite this paper as: Bozkurt M, Kara D. Fetus papyraceous in a twin pregnancy: a case report without any maternal and fetal complications. Proc Obstet Gynecol. 2013;3(2):Article 4 [ 5 p.]. Available from: http://ir.uiowa.edu/pog /. Free full text article.

Corresponding author: Murat Bozkurt, Universal Malatya Hastanesi, Turgut Ozal Bulvari Ankara Asfalti 6.km No:216 44000 MALAYTA/TURKEY. Telephone 904222382828/1546. Fax: 904222382600. jindrmb@yahoo.com.

Financial Disclosure: The authors report no conflict of interest.

Received: 2 August 2012; received in revised form:21 October 2012; accepted 15 November 2012; POG in Press, 23 January 2013; published online, 3 July 2013.

This is an Open Access article distributed under the terms of the Creative Commons Attribution 3.0 Unported License (http://creativecommons.org/licenses/by/3.0), which permits unrestricted use, distribution, and reproduction in any medium, provided the original work is properly cited. 
days); head circumference, $336 \mathrm{~mm}$ (38 weeks, 1 day); fetal heart rate, 148 beat $/$ min. In addition, the amniotic fluid volume was within the normal range and the placenta was located in an anterior position. The patient's clinical and laboratory examinations were normal. On vaginal examination, the cervical dilatation was $8 \mathrm{~cm}$ with $80 \%$ effacement. There was single fetus with cephalic presentation and left occipitoanterior position. Fetal membrane was intact.

Subsequently, the patient was admitted into the delivery room, and the membranes ruptured spontaneously. The patient delivered a $3200 \mathrm{~g}$ fetus with a 1 minute Apgar score of 7 and a 5 minute Apgar score of 9. Appearance of the fetus was normal.

The placenta was delivered carefully. Inspection of the placenta showed one healthy placenta and umbilical cord of the healthy baby. The normal placenta weighted $375 \mathrm{~g}$. A rudimentary cord was attached to the placenta with a compressed, mummified fetus that was identified as a fetus papyraceous (FP). The FP weight was nearly $200 \mathrm{~g}$ and measured $15 \mathrm{~cm}$ in length (Figure 1). Thus, the pregnancy was diamniotic and dichorionic. No complications were observed in the postpartum period. Both mother and baby were discharged one day later. At six-month follow-up, no abnormalities were observed in the mother or baby.

\section{DISCUSSION}

FP is an uncommon condition seen 1 in 17,000 to 20,000 pregnancies. ${ }^{1}$ It occurs in multiple gestation pregnancies, and the other fetus(es) continue to grow and are born healthy. FP is tiny, mummified, and parchment-like because the amniotic fluid and fluid content of the dead fetal tissue and placental tissue are absorbed, and the dead fetus is flattened and compressed between the membranes. FP is an uncommon finding in multiple gestation pregnancies. This condition can have adverse effects to both the mother and remaining fetus(es) during pregnancy. Diagnosis of FP is important to predict for future obstetric complications and to predict the risk of mortality and morbidity for the surviving fetus(es).

Prior to antenatal visits and use of ultrasound examination, the diagnosis of FP was only possible after delivery. The advent of real time ultrasound using the intravaginal probe permitted the diagnosis of multiple gestation as early as four weeks after conception. ${ }^{1}$ In late second and third trimesters, it is not always possible to diagnose FP by ultrasound examination.

In our case we report a diamniotic and dichorionic pregnancy. Perinatal mortality of monochorionic twin pregnancies is higher than with dichorionic twin pregnancies. A study by McPherson and colleagues investigated the association between chorionicity and intrauterine fetal demise (IUFD) of one or both fetuses in twin pregnancies. The study was performed on 2161 twin pregnancies; 86 had at least 1 IUFD and 32 had a double fetal loss. Consequently, they found that monochorionic pregnancies had an increased risk of a single demise (adjusted odds ratio, 1.69; 95\% confidence interval, 1.04-2.75) and a double demise (adjusted odds ratio, 
2.11; 95\% confidence interval, 1.02happened before 24 weeks. They have been put forward that monochorionic twins carry an increased risk of fetal death compared to dichorionic twins. Similarly, double demise occurs primarily before 24 weeks of gestation, to the detriment of chorionicity. ${ }^{2}$ A study performed by Dickey, et al., investigated that the association between the number of fetuses and fetal demise. It has been seen that spontaneous reduction of one or more gestational sacs and or embryos occurred before the 12 th week of gestation in $36 \%$ of
4.37). $70 \%$ of all double demises twin, $53 \%$ of triplet, and $65 \%$ of quadruplet pregnancies. ${ }^{3}$ In another study, fetal death at 20 weeks' gestation or later was rare, occurring in $2.6 \%$ of twin and $4.3 \%$ of triplet gestations. The data obtained from this study showed that the survival of the remaining fetuses was inversely related to the time of the first fetal demise, and an increased risk of fetal death was associated with monochorionic placenta, disproportionate sharing of placenta, and monozygosity. ${ }^{4}$

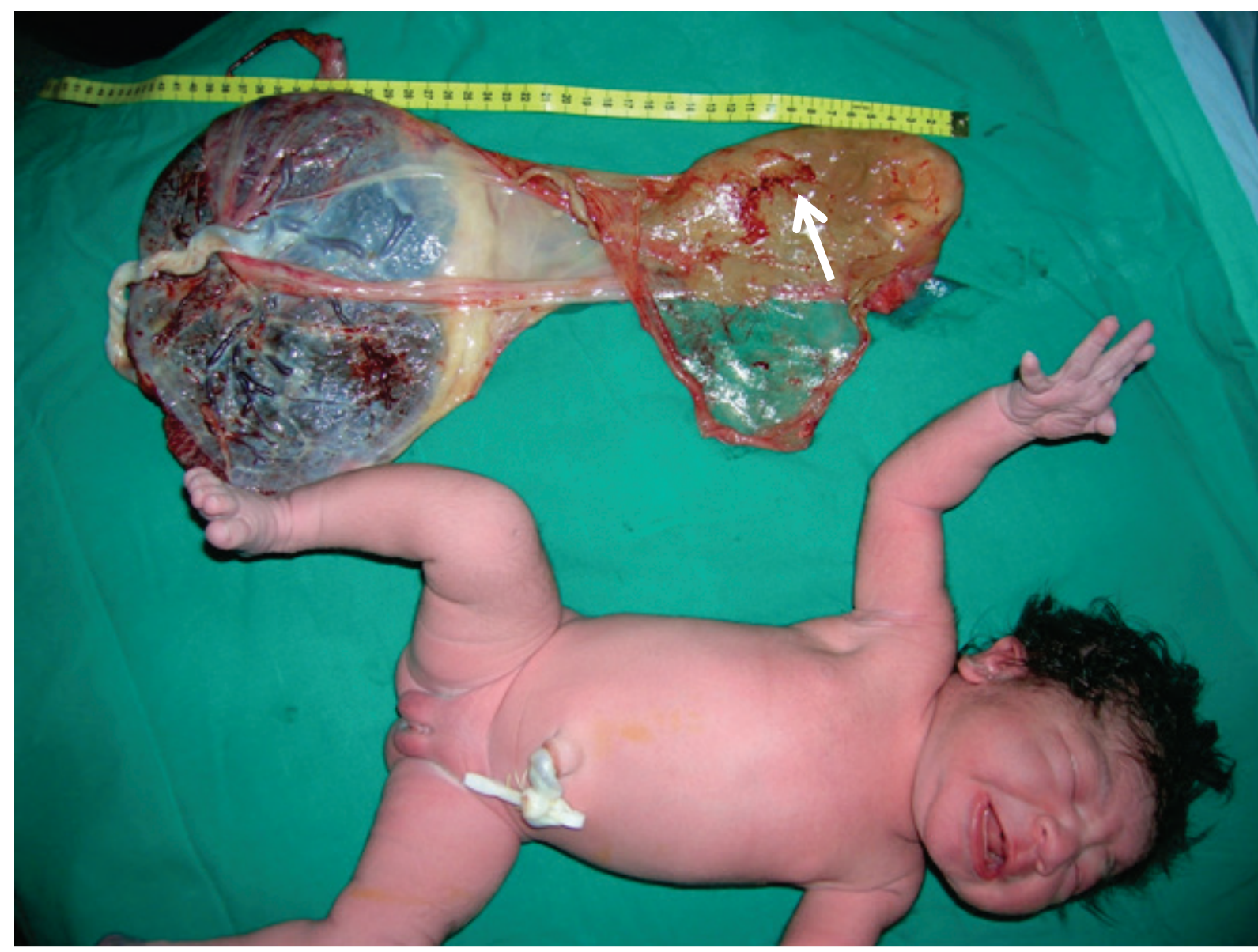

Figure 1: Normal baby with fetus papyraceous. White arrow shows the fetus papyraceous. 
Fetal death of the co-twin in the first trimester of pregnancy is a relatively common event; fetal death in the second trimester is rare and carries risks for the surviving fetus and the mother.

The rare complications of FP on the surviving twin include intrauterine growth restriction, congenital disorders, cord complications, pre-term labor and prematurity. The congenital disorder of multicystic encephalomalacia occurs in $20 \%$ of surviving co-twins and is a result of severe fetal hypotension and hypoxia, which contributes to the increased morbidity of the surviving twin. Another study in the literature showed that, the risk of serious cerebral impairment in the surviving twin following fetal death is about $20 \%$. Also, the prevalence of cerebral palsy after fetal death of the cotwin is much more than that reported for the general twin population. The twin embolization syndrome is another serious complication that occurs in $25 \%$ of surviving twins after fetal demise of the co-twin. $5,6,7$ Twin embolization syndrome can be a result of several events, including embolization of placental and fetal thromboplastins, the direct embolization of necrosed fragments of the placenta from the dead fetus, disseminated intravascular coagulation, or even infectious endarteritis. The emboli can damage the brain and kidneys; damage to other organ systems can result in central nervous system abnormalities like ventriculomegaly, porencephaly, cerebral atrophy, cystic encephalomalacia or microcephaly and extracranial abnormalities including small bowel atresia, gastroschisis, hydrothorax, aplasia cutis and renal cortical necrosis. ${ }^{7}$ Dystocia is possible when the fetus papyraceous lies transversely in pelvis below the surviving twin. ${ }^{8}$ During the delivery FP may lead to rare obstetrical complications like obstructed labor and delay or obstruction the placental delivery. ${ }^{9}$ A tiny flattened fetus may be discovered within the membrane and/or in the placenta. It is important when searching for FP or other placental pathologies that inspection of the placenta is done carefully. In the case study presented herein, it was possible that any of these major and minor complications may have occurred, but none were observed. We believed that this case may be related with the death of the fetus in the early second trimester.

\section{CONCLUSION}

In conclusion, we report a case of FP with no maternal and fetal complications during pregnancy and the post-partum period. The etiology of the FP could not be explained. Routine ultrasound examination with better training and use of modern ultrasound machines with good resolution is important for detection of multiple gestations. This will allow the diagnosis of FP early in pregnancy and may prevent future obstetrical complications and reduce the risk of mortality and morbidity for the surviving fetus.

This study presented in Turkey Maternal Fetal Medicine and Perinatalogy Association VIIIth National Congress 11th - 14th October 2012 Harbiye Askeri Müze, ISTANBUL 


\section{References}

1. Bush M, Pernoll ML. Multiple pregnancy. In: DeCherney $A H$, Nathan L (eds). Current obstetric and gynecologic diagnosis and treatment. McGraw-Hill, New York. 2003; 315 -325.

2. McPherson JA, Odibo AO, Shanks AL, Roehl KA, Macones GA, Cahill AG. Impact of chorionicity on risk and timing of intrauterine fetal demise in twin pregnancies. Am J Obstet Gynecol. 2012 Sep;207(3):190.e1-6. doi: 10.1016/j.ajog.2012.07.031. Epub 2012 Jul 27. PubMed PMID: 22939722.

3. Dickey RP, Taylor SN, Lu PY, Sartor BM, Storment JM, Rye PH, Pelletier WD, Zender JL, Matulich EM. Spontaneous reduction of multiple pregnancy: incidence and effect on outcome. Am J Obstet Gynecol. 2002 Jan;186(1):77-83. PubMed PMID: 11810089.

http://dx.doi.org/10.1067/mob.2002.118 915

4. Johnson CD, Zhang J. Survival of other fetuses after a fetal death in twin or triplet pregnancies. Obstet Gynecol. 2002 May;99(5 Pt 1):698-703. PubMed PMID: 11978275.

http://dx.doi.org/10.1016/S0029-

7844(02)01960-9

5. Weiss JL, Cleary-Goldman J, Tanji K, Budorick N, D'alton ME. Multicystic encephalomalacia after first-trimester intrauterine fetal death in monochorionic twins. Am J Obstet Gynecol. 2004 Feb;190(2):563-5. PubMed PMID: 14981409. http://dx.doi.org/10.1016/S00029378(03)00824-X

6. Pharoah PO, Adi Y. Consequences of in-utero death in a twin pregnancy. Lancet. 2000 May 6;355(9215):1597602. PubMed PMID: 10821363. http://dx.doi.org/10.1016/S01406736(00)02215-7
7. Upadhyaya I, Pradhan M, Sharma R. Twin pregnancy with fetus papyraceous. JNMA J Nepal Med Assoc. 2009 JulSep;48(175):246-8. PubMed PMID: 20795467.

8. Woo HH, Sin SY, Tang LC. Single foetal death in twin pregnancies: review of the maternal and neonatal outcomes and management. Hong Kong Med J. 2000 Sep;6(3):293-300. PubMed PMID: 11025849.

9. Koregol MC, Nayak R, Kandasamy S, Bhandary A, Mahale N, Dodawad A. Fetus papyraceous: a rare cause for obstruction to spontaneous placental expulsion. Arch Gynecol Obstet. 2009 Jun;279(6):945-7. doi: 10.1007/s00404009-0930-6. Epub 2009 Jan 17. PubMed PMID: 19151989. 